\title{
5. SITE SURVEY AND UNDERWAY GEOPHYSICS ${ }^{1}$
}

\author{
Shipboard Scientific Party ${ }^{2}$
}

\section{SEISMIC SITE SURVEY}

The site survey for Ocean Drilling Program (ODP) Leg 166 consisted of a high-resolution, multichannel seismic survey that covered a wide area around and along the main transect with all deep drill sites and the area of the southern sites. The seismic data were acquired from the Lone Star in June 1994 in cooperation with Rice University, Houston, Texas, U.S.A. A 45 -in ${ }^{3}$ G.I. air gun was used at 2$\mathrm{m}$ water depth and $2200 \mathrm{psi}$, in combination with a 600-m-long, 24channel streamer positioned at 3- to 4-m depth. The seismic signal generated by the air gun had a frequency band of $20-500 \mathrm{~Hz}$, with the high energies between 40 and $200 \mathrm{~Hz}$. The 12-fold data were processed using the ITA software package and interpreted using the LANDMARK 2-D SEISWORKS package. All multichannel seismic lines were filtered (time-variant bandpass filter) and migrated before interpretation.

\section{UNDERWAY GEOPHYSICS}

Although a dense grid of high-resolution, multichannel seismic data already existed in the area of the drill sites, we decided to conduct a short, clover-leaf-shaped single-channel seismic survey, which connects the Bahamas Transect Sites 1003, 1004, 1005, and 1007 (Fig. 1). These data complement the pre-cruise, high-resolution, multichannel seismic survey in the following ways:

1. Comparison of the high-resolution site survey data, the medium-resolution underway seismic data, and the low-resolution Western Geophysical multichannel seismic line (see "Introduction" chapter and Eberli et al., this volume), will enable us to assess the frequency dependence of the seismic image by recording the hierarchy in the stacking pattern of seismic sequences.

2. In the uppermost sediment layers, single-channel seismic data can result in higher resolution and clearer geometries than with stacked multichannel seismic data, which typically show some smearing in shallow nonhorizontal layers.

3. The differential global positioning system (GPS) used aboard the JOIDES Resolution resulted in more accurate positions than obtained during the multichannel campaign in 1994, which used a conventional GPS for navigation. The new data allowed for an accurate verification of the bathymetry and seismic character at the drill sites.
${ }^{1}$ Eberli, G.P., Swart, P.K., Malone, M.J., et al., 1997. Proc. ODP, Init. Repts., 166: College Station, TX (Ocean Drilling Program).

${ }^{2}$ Shipboard Scientific Party is given in the list preceding the Table of Contents.

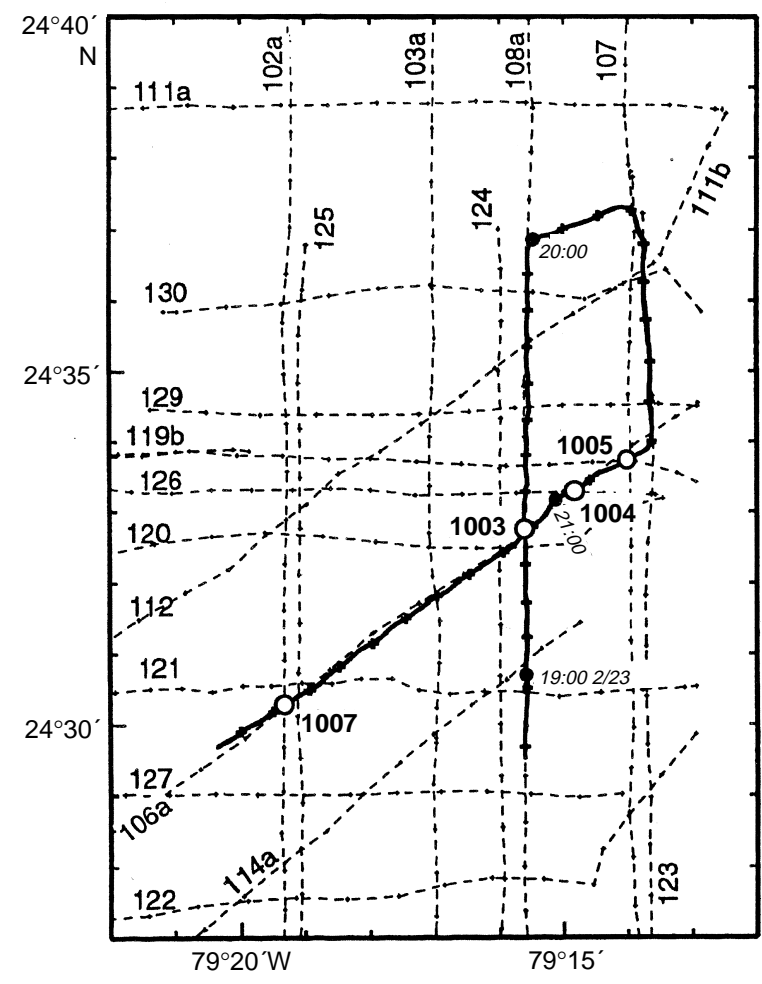

Figure 1. Location of seismic profiles. Thin dashed lines with crosses correspond to pre-cruise seismic reflection data collected on the Lone Star with respective line numbers. The thick line is the time-annotated site survey track of seismic reflection data shot from the JOIDES Resolution during Leg 166.

\section{RECORDING PARAMETERS}

On 23 February, just before we reached Site 1003, a single-channel streamer was deployed port-side and kept at a water depth of 8-9 $\mathrm{m}$. Initially, a $200-\mathrm{in}^{3}$ water gun was used port-side at a pressure of $1500 \mathrm{psi}$ and a water depth of $12 \mathrm{~m}$. Halfway through the survey, at 1949 UTC, we switched to an 80 -in ${ }^{3}$ water gun (at 2000 psi pressure) positioned starboard at a depth of 6-7 m. The second setting produced a clearer signal and a better penetration and, consequently, was chosen for the remainder of the survey. The shooting interval was kept constant at $8 \mathrm{~s}$. Data were recorded digitally from 1853 to 2154 UTC, and subsequently processed aboard by SIOSEIS software (bandpass filter $20 \mathrm{~Hz}-150 \mathrm{~Hz}$, AGC $500 \mathrm{~ms}$ applied in the center, trace mixing with weights $1,2,1)$. The processed line with imaged sites is shown in Figure 2. 


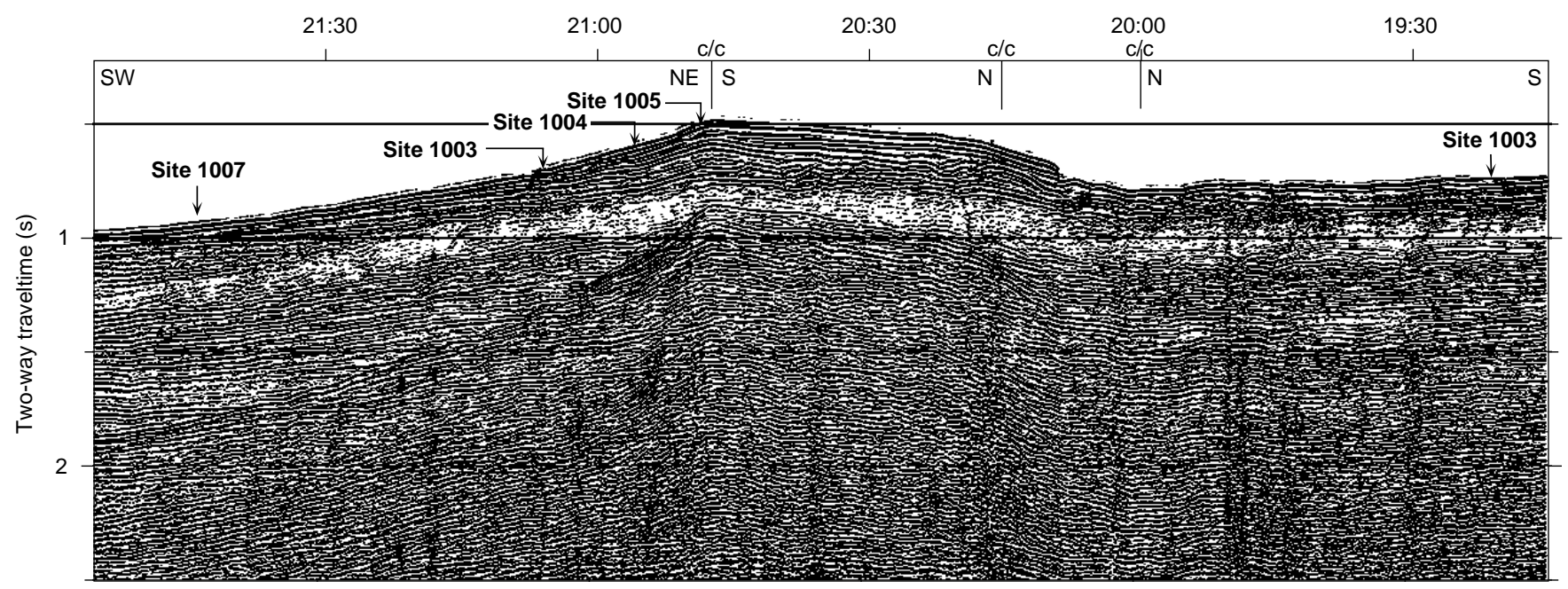

Line JR166-1

Figure 2. Seismic reflection line showing location of sites on the shallower portion of the Bahamas Transect, ODP Leg 166. Location of profile in Figure 1. 